\title{
Use of the flexible bronchoscope and Infrared Red Intubation System in a known difficult airway in the Intensive Care Unit
}

\author{
Kjartan Eskjaer Hannig ${ }^{1}$, Michael Kristensen ${ }^{2}$, Rasmus Hauritz ${ }^{3}$, Christian Jessen ${ }^{4}$, and \\ Anders Grejs ${ }^{5}$ \\ ${ }^{1}$ Sygehus Lillebalt Kolding Sygehus \\ ${ }^{2}$ Copenhagen University Hospital Centre of Head and Orthopaedics \\ ${ }^{3}$ Kolding Hospital \\ ${ }^{4}$ Regional Hospital Horsens \\ ${ }^{5}$ Aarhus University Hospital
}

February 20, 2022

\begin{abstract}
This case report describes a patient in the ICU in need of urgent intubation, for whom video laryngoscope-guided intubation had previously failed. The Infrared Red Intubation System may enhance the chance of successful flexible bronchoscope intubation, especially when performed by non-experts in hospitals without ear, nose and throat surgical backup.
\end{abstract}

\section{INTRODUCTION}

Some patients cannot be intubated with a hyperangulated videolaryngoscope (HA-VL)..$^{1-4}$

This case-report describes a patient in respiratory failure requiring acute intubation, with previous impossible HA-VL intubation. If invasive techniques are to be avoided, acute Awake Tracheal Intubation with a Flexible Bronchoscope (ATI-FB) may be the best option. ${ }^{1,3,4}$

The Infrared Red Intubation System (IRRIS - Guide In Medical, Nazareth, Israel) ${ }^{5}$ may enhance the chances of success, especially, if the ATI-FB has to be performed by non-expert anaesthesiologists, who only infrequently perform FB.

\section{CASE PRESENTATION}

A 49-year-old woman $(144 \mathrm{~cm} ; 60 \mathrm{~kg})$ experienced spontaneous, upper leg pain. She was bedridden with gradually worsening of dyspnea and finally called an ambulance.

In early childhood the patient was diagnosed with severe juvenile idiopathic arthritis. She had undergone multiple previous surgeries all of which were performed with ATI-FB. At one occasion, after securing the airway, inducing unconsciousness and neuromuscular relaxation, attempts at introducing a HA-VL (McGrath-MAC $\mathrm{X}$-Blade ${ }^{\mathrm{TM}}$, Medtronic, MN, USA) were unsuccessful due to severely limited mouth opening.

In the emergency department the patient was diagnosed with a femoral fracture and pneumonia (Fig. 1). She deteriorated and was transferred to the intensive care unit. The respiratory rate was $40 \mathrm{breaths} / \mathrm{min}$, peripheral oxygen saturation was 88-95\% (with $5 \mathrm{~L} / \mathrm{min}$ oxygen delivered via nasal cannula), heart rate was 120 beats/min, and blood pressure was $130 / 70 \mathrm{mmHg}$. Intermittently, the patient could still follow commands (such as squeezing a hand), but no longer opened her eyes or responded verbally. After Noninvasive Ventilation (NIV) on maximal settings, her arterial gas showed pO2 at $8.2 \mathrm{kPa}, \mathrm{pCO} 2$ at $12.8 \mathrm{kPa}$, 
$\mathrm{pH}$ at 7.30 , lactate at $0.6 \mathrm{mmol} / \mathrm{L}$, and base excess at $13.1 \mathrm{mmol} / \mathrm{L}$. Airway examination revealed a mouth opening of $13 \mathrm{~mm}$, severely limited neck movement $\left(<80^{\circ}\right)$, severe retrognathia, and a short neck that was difficult to palpate (Fig. 1).

The patient was positioned upright sitting and preoxygenated with NIV, followed by high-flow nasal oxygen (HFNO) for the intubation itself. Glycopyrrolate $0.2 \mathrm{mg}$ (Meda, Solna, Sweden) was administered slowly intravenously. The cricothyroid membrane was identified and marked. Sedation was achieved with midazolam $0.25 \mathrm{mg}$ (Hameln, Hameln, Germany) and s-ketamine $5 \mathrm{mg}$ (Pfizer, Ixelles, Belgium), which were both titrated slowly and administered intravenously. For the sake of speed and simplicity, lidocaine $2 \%$ with epinephrine $5 \mu \mathrm{g} / \mathrm{ml}$ (Amgros, Copenhagen, Denmark) was used for topicalisation supplemented with spray application of lidocaine 10\% (Xylocaine Pump Spray $100 \mathrm{mg} / \mathrm{ml}$, AstraZeneca, Södertälje, Sweden). Nebulisation on the NIV machine $(5 \mathrm{ml} \times 2)$, spray application $(3$ puffs $\times 2)$, transtracheal injection $(2 \mathrm{ml} \times 1)$, infiltration superficially to the cricothyroid membrane $(3 \mathrm{ml} \times 1)$, nasal atomising (MAD Nasal ${ }^{\mathrm{TM}}$, Teleflex, Waine, PA, USA), and direct nasal application with a local anaesthetic soaked ribbon gauze $(1 \mathrm{ml} \times 2$ and $5 \mathrm{ml} \times 1$, respectively) were applied. Intubation was then performed with an FB (Ambuß)aScope Regular, Ambu, Ballerup, Denmark), a Portex(r)Soft Seal(r) tracheal tube with an internal diameter of $7.0 \mathrm{~mm}$ (Smiths Medical, Minneapolis, MN, USA) and a size 8-cm Berman Intubating Airway (Vital Signs, Totowa, NJ, USA), which maximally compressed could just be inserted between the teeth. The flashing bright light from the IRRIS momentarily allowed identification of the relevant structures. During the procedure (see Supplemental Video S1), vital signs remained stable including peripheral saturations at $85-95 \%$. Total time from initiation of topicalisation to successful intubation was 13 minutes, whereas the intubation itself took less than 2 minutes. Visual confirmation of tube placement, gentle cuff inflation and immediate capnography were followed by propofol infusion and initiation of mechanical ventilation.

\section{DISCUSSION}

Guidelines for the management of known difficult airways ${ }^{1,6}$ and for intubation in critically ill adults ${ }^{7}$ have been published.

In known difficult airways ATI is still considered the standard approach. ${ }^{1,2,6,8}$ The benefits of ATI are, that spontaneous breathing is preserved (hence oxygenation), that the patient can be sitting up (thus providing maximal airway diameter and avoiding atelectasis) and that there is some protection against aspiration (preserved reflexes and muscle tone). ${ }^{2,6}{ }^{8}$ Traditionally, ATI is performed with a FB. ${ }^{1,2,6,8}$

The VL revolutionised airway management, since even previously difficult airways only manageable with the FB now often were manageable with the VL. Accordingly, awake airway techniques and FB intubation skills in particular may have become less frequently needed/practiced by the typical anaesthesiologist and are underutilised techniques. ${ }^{9}$ Prior to the widespread adoption of VL's, only approximately $50 \%$ of anaesthesiologists considered themselves to be skilled in FB intubation. ${ }^{10}$ Reluctance to perform ATI-FB may be because of lack of training and concerns related to time delay and patient discomfort. ${ }^{6,8,9}$ With the right preparations though, the time spent on the procedure is acceptable ${ }^{2,11,12}$ and most patients do not experience discomfort. ${ }^{2}, 11,13,14$

If ATI-FB, performed by a non-expert anaesthesiologist is required, considerations should be made early before the patient's physiological status has deteriorated. The cricothyroid membrane should be identified (if necessary guided by ultrasound) and marked in advance in the extended-neck position. ${ }^{2,}{ }^{15}$ The patient should be positioned upright sitting and face-to-face with the anaesthesiologist, providing both maximal luminal patency and maximal patient comfort and, hence, a reduced need for sedation. ${ }^{3,4,6}$

The most common problems with acute ATI-FB in critically ill patients may be categorized as follows:

1. Problems with oxygenation/circulation

2. Problems with inadequate sedation/topicalisation

3. Problems with visibility of relevant structures

4. Problems with tube advancement 


\section{Impossible FB intubation necessitating a backup strategy}

Preoxygenation can be achieved using NIV with 100\% oxygen while performing sedation/topicalization ${ }^{7}$, NIV can be changed to HFNO at $100 \%$ oxygen and maximal flow, for the intubation itself. The patient should be fully monitored, including a-line and large bore venous line (if time permits central venous line) and vasopressors/inotropes should be ready and used proactively. ${ }^{7}$

In the elective ATI-FB, no superior sedation/topicalisation regime has been identified. ${ }^{8}$ In the critically ill, a non-opioid based regime could theoretically provide a safety benefit and minimal sedation should be titrated cautiously. Over-sedation would be dangerous due to the risk of secondary airway obstruction, hypoventilation/hypoxia, and circulatory collapse. ${ }^{6,8}$ Optimal airway topicalisation is the key to success. ${ }^{2,} 6,8$ Oral intubation is preferred to avoid epistaxis ${ }^{2}$, and to employ a sufficiently large tube size, if a period of ventilator therapy is expected. As last resort plans, the nasal route is prepared from the start (backup if oral route access fails) and subcutaneous local anaesthetics can be placed superficially to the cricothyroid membrane (backup if invasive techniques have to be performed). The maximal dose of topical lidocaine is 9 $\mathrm{mg} / \mathrm{kg} .1,6$

The visibility of relevant structures is enhanced if the upper airway diameter is enlarged, secretions and blood do not obscure the vision with the FB, and the glottis and vocal cords can be identified expediently. Simple maneuvers can contribute to this (Fig. 1). The upright sitting position has the most significant impact on airway patency. ${ }^{6}$ Specialized oral airways for FB's (e.g. Berman), increase the upper airway diameter, but insertion might be impossible in cases of severely limited mouth opening. If the patient's cerebral status deteriorates (or due to over-sedation), biting on the FB or tube may make oral intubation impossible. Insertion of an oral airway, bite block, or a HA-VL blade intraorally as conduit for the FB may alleviate this problem (otherwise the nasal route can be considered). Thick purulent secretions can cover the mucosal surfaces thus acting as a mechanical barrier for optimal topicalisation of these areas and can hinder visualisation with the FB. Cautious suctioning should thus be performed before topicalisation. Early administration of an antisialologue (e.g., glycopyrrolate), has a mucosal drying effect and vasoconstrictor agents applied to the mucosa (especially nasally) can minimise epistaxis. ${ }^{6}$ Retrograde light-guided laryngoscopy is not a new idea; a method with direct laryngoscopy and a flashlight held on the front of the neck has previously been published. ${ }^{16,17}$ When IRRIS is placed superficial to the patient's cricothyroid membrane or trachea, it emits flashing infrared light through the skin. ${ }^{5}$ When a FB is introduced into the airway, the infrared light will become visible as a flashing white light on the FB's video-screen, showing the pathway to the vocal cords and trachea. ${ }^{5}$ IRRIS has been shown beneficial in the elective VL-guided intubation of lean respectively extreme obese patients ${ }^{18,19}$, elective ATI-FB in known difficult airways ${ }^{20}$ and in ATI-FB of an obstetric patient with a known difficult airway ${ }^{4}$.

The incidence of tube impingement is reduced, if specialized tubes are used (e.g., LMA(r)Fastrach ETT, Teleflex, Beaconsfield, UK), the opening of the bevel is oriented posteriorly and the gap between the tube and the FB is minimised. ${ }^{6}$

In hospitals with ear, nose and throat (ENT) surgical expertise, awake surgical tracheostom y would have been a viable backup option and could also have represented the primary plan. ${ }^{2,3}$ In hospitals without ENT surgical backup as in this case, immediate relocation of the patient with NIV to another hospital can be considered, if the clinical status is expected to be very stable for the duration of the transport. If acute ATI-FB is attempted and fails, awake cricothyroidotomy (by an anaesthesiologist) or awake percutaneous dilatational tracheostomy (by an experienced intensivist) can be considered. ${ }^{3}$ Emergency cricothyroidotomy after high-risk general anaesthesia with full relaxation should remain the last resort, since failure rates may be over $50 \%$ when performed by an anaesthesiologist in a 'cannot-intubate-cannot-oxygenate' situation. ${ }^{9}, 11$

\section{CONCLUSION}

Optimally, expert anaesthesiologists should manage intubation of patients, who cannot be intubated with a HA-VL. In a time-critical setting where non-experts need to perform the acute ATI-FB, without ENT surgical backup, IRRIS may enhance the probability of success. 


\section{AUTHOR CONTRIBUTIONS}

KEH: Performing the procedure, drafting and revising the article. MSK, RWH, CJ, AMG: Revising the article. All authors have read and approved the final manuscript and agreed to be accountable for all aspects of the work.

\section{REFERENCES}

1. Law J. A., Duggan L.V., Asselin M. et al. 2021. Canadian Airway Focus Group updated consensusbased recommendations for management of the difficult airway: part 2. Planning and implementing safe management of the patient with an anticipated difficult airway. Canadian Journal of Anesthesia https://doi.org/10.1007/s12630-021-02008-z.

2. Aziz M. F., Kristensen M.S. 2020. From variance to guidance for awake tracheal intubation. Anaesthesia 75: $442-446$.

3. Hannig K. E., Hauritz R. W., Jessen C., Grejs A. M. 2019. Acute awake fiberoptic intubation in the ICU in a patient with limited mouth opening and hypoxemic acute respiratory failure. Case Reports in Anesthesiology Article ID 6421910, https://doi.org/10.1155/2019/6421910.

4. Hannig K. E., Hauritz R. W., Jessen C., Herzog J., Grejs A. M., Kristensen M. S. 2021. Managing known difficult airways in obstetric patients using a flexible bronchoscope and IRRIS: A case-illustrated guide for non-expert anesthesiologists, without surgical backup. Case Reports in Anesthesiology Article ID 6778805, https://doi.org/10.1155/2021/6778805

5. Kristensen M. S., Fried E., Biro P. 2018. Infrared Red Intubation System (IRRIS) guided flexile videoscope assisted difficult airway management. Acta Anaesthesiologica Scandinavica 62: 19-25.

6. Ahmad I., El-Boghdadly K., Bhagrath R. et al. 2020. Difficult Airway Society guidelines for awake tracheal intubation (ATI) in adults. Anaesthesia 75: 509-528.

7. Higgs A., McGrath B. A., Goddard C. et al. 2018. Guidelines for the management of tracheal intubation in critically ill adults. British Journal of Anaesthesia 120:323-352.

8. Cabrini L., Redaelli M. B., Ball L. et al. 2019. Awake fiberoptic intubation protocols in the operating room for anticipated difficult airway: a systematic review and meta-analysis of randomized controlled trials. Anesthesia \& Analgesia 128: 971-980.

9. Cook T. M., Woodall N., Frerk C. 2011. Forth National Audit. Major complications of airway management in the UK: results of the Fourth National Audit Project of the Royal College of Anaesthetists and the Difficult Airway Society. Part 1: anaesthesia. British Journal of Anaesthesia 106:617-31.

10. Ezri T., Szmuk P., Warters R. D., Katz J., Hagberg C. A. 2003. Difficult airway management practice patterns among anesthesiologists practicing in the United States: have we made any progress? Journal of Clinical Anesthesia 15:418-422.

11. Hannig K. E., Jessen C., Hauritz R. W., Grejs A. M. 2018. Awake fiberoptic intubation in fast track ambulatory surgery: A case report. A\&A Practice 11: 165-168.

12. Joseph T. T., Gal J. S., DeMaria S. et al. 2016. A retrospective study of success, failure, and time needed to perform awake intubation. Anesthesiology 125: 105-114.

13. Schnack D. T., Kristensen M. S., Rasmussen L. S. 2011. Patient's experience of awake versus anaesthetised orotracheal intubation: a controlled study. European Journal of Anaesthesiology 28: 438-442.

14. Archer C., Veall J. Duggan L. V. et al. 2022. A comparison of patient and provider perceptions of awake tracheal intubations. Canadian Journal of Anesthesia 69: 179-181.

15. Kristensen M. S., Teoh W. H. 2021. Ultrasound identification of the cricothyroid membrane: the new standard in preparing for front-of-neck airway access. British Journal of Anaesthesia 126: 27-30. 
16. Hudson J., Vu M., Vu E. 2010. Successful intubation using retrograde trans-tracheal illumination after laryngoscope light source failure. British Journal of Anaesthesia 105: 96-97.

17. Yang T., Hou J., Li J. et al. 2013. Retrograde light-guided laryngoscopy for tracheal intubation. Anesthesiology 118: 1059-1064.

18. Biro P., Fried E., Schlaepfer M., Kristensen M. S. 2018. A new retrograde transillumination technique for videolaryngoscopic tracheal intubation. Anaesthesia 73:474-479.

19. Godoroja D. D., Copaescu C. A., Agache M. C., Biro P. 2020. Impact of retrograde transillumination while securing the airway in obese patients undergoing bariatric surgery. Journal of Clinical Monitoring and Computing 34: 1069-1077.

20. Jauho K. R., Johannsen M. L., Hesselfeldt R. T., Kristensen M. S. 2021. Infrared flashing light through the cricothyroid membrane to guide flexible bronchoscopic tracheal intubation. Anaesthesia Reports 9: 114-

Figure 1: The patient's chest X-ray before intubation showing bilateral pneumonia, atelectasis, and severe scoliosis with a Harrington rod (A). The patient after intubation - Infrared Red Intubation System placed on outer trachea (B). The patient after extubation, demonstrating maximal mouth opening of $13 \mathrm{~mm}(\mathrm{C})$.

Figure 2: Flexible bronchoscope view of a normal airway in a healthy man (43 years; $195 \mathrm{~cm} ; 90 \mathrm{~kg}$ ).

Upright sitting position with optimal airway diameter.Additional maneuvers for optimising visibility of relevant structures (since vocal cord movements or air bubbles may become visible): Normal breathing (A.1), 'take a deep breath' (A.2), Valsalva maneuver (A.3) and 'say eee' (A.4).

Supine position with partial airway collapse. Maneuvers for optimising airway diameter: Normal breathing (B.1), 'stick out tongue' (B.2), 'jaw thrust' (B.3) and continuous positive airway pressure with high-flow nasal oxygenation with maximal flow (B.4).

Infrared Red Intubation System (IRRIS). For optimising visibility of relevant structures: Turned off (C.1), turned on - normal breathing (C.2), turned on - deep breath (C.3) and seen from the outside - placed on upper trachea (C.4).

\section{SUPPORTING INFORMATION}

Supplemental Video S1: Flexible bronchoscope intubation of the patient (with a known difficult airway). The patient is in the upright sitting position. The anaesthesiologist is facing the patient.

\section{Hosted file}

Figure 1_190122.docx available at https://authorea.com/users/461447/articles/557158-useof-the-flexible-bronchoscope-and-infrared-red-intubation-system-in-a-known-difficultairway-in-the-intensive-care-unit

\section{Hosted file}

Figure 2_190122.docx available at https://authorea.com/users/461447/articles/557158-useof-the-flexible-bronchoscope-and-infrared-red-intubation-system-in-a-known-difficultairway-in-the-intensive-care-unit 